\title{
Inflammation as a target for improving health in chronic kidney disease Peter Stenvinkel
}

Address: Division of Renal Medicine, K56, Karolinska University Hospital at Huddinge, 14186 Stockholm, Sweden Email: peter.stenvinkel@ki.se

Fl000 Medicine Reports 2010, 2:88 (doi:10.3410/M2-88)

This is an open-access article distributed under the terms of the Creative Commons Attribution-Non Commercial License (http://creativecommons.org/licenses/by-nc/3.0/legalcode), which permits unrestricted use, distribution, and reproduction in any medium, provided the original work is properly cited. You may not use this work for commercial purposes.

The electronic version of this article is the complete one and can be found at: http://f $1000 . c o m / r e p o r t s / m / 2 / 88$

\begin{abstract}
Since the first reports in the late 1990s connecting elevated circulating levels of C-reactive protein in patients with end-stage renal disease with an atherogenic, wasted phenotype and poor outcome, more than 3600 publications related to the subject have appeared on the Medline bibliographic database. This reflects the exponential interest that this topic has evoked in the field of nephrology, and the possibility of treating this common uremic complication has been much discussed. Several small studies have implied that various nutritional and pharmacological treatment strategies have beneficial effects on surrogate markers of inflammation. However, no randomized controlled trials on anti-inflammatory treatment have yet been performed to test the hypothesis that persistent lowgrade inflammation contributes to uremic morbidity and mortality.
\end{abstract}

\section{Introduction and context}

As the majority of recent randomized controlled trials (RCTs) have been unable to demonstrate a beneficial effect of various interventions aimed at improving outcome in end-stage renal disease (ESRD) [1], novel treatment strategies need to be tested in this high-risk patient group. Among several novel risk factors, inflammation has attracted considerable interest in the last 10 years [2]. Although cytokine production is necessary to protect against pathogens and promote tissue repair, excessive release or decreased clearance (or both) can lead to organ failure and premature death. Detailed reviews on causes of inflammation in the context of impaired renal function have recently been published $[2,3]$. Prospective studies in hemodialysis, peritoneal dialysis, and renal transplantation patients show that even a single measurement of inflammatory biomarkers independently predicts poor outcome [2]. Furthermore, inflammation has been identified as a strong prognosticator of sudden death in ESRD patients [4], which indirectly supports a link between persistent inflammation and an imbalance between the sympathetic and parasympathetic nervous system [5].
In 2008, a large genetic study of patients with ischemic heart disease (and controls) showed that C-reactive protein (CRP) polymorphisms are not in themselves associated with an increased risk of ischemic vascular disease, therefore, available evidence suggests that although CRP is a strong risk marker, it is not a risk factor of cardiovascular disease [6]. In fact, among numerous studies that have shown that inflammatory biomarkers or cells involved in the inflammatory cascade predict outcome, interleukin (IL)- 6 seems to be the strongest predictor of cardiovascular morbidity and outcome [7]. Another study showed that by defining specific cytokine ratios related to the inflammatory and immunologic states, it seems possible to fine tune the prediction of death from cardiovascular and non-cardiovascular causes [8]. Based on the observation that persistent inflammation may serve as a catalyst and magnify the risk of poor outcome via mechanisms related to self-enhancement of the inflammatory cascade and exacerbation of the wasting and calcification processes [3], it can be argued that the effects of different interventions should be analyzed separately in inflamed and non-inflamed dialysis patients. 


\section{Recent advances}

Although inflammatory markers persistently predict outcome in dialysis patients or following kidney transplantation, few studies have studied the effect of various anti-inflammatory interventions on outcome [2]. However, as small studies have shown encouraging results after examining the levels of inflammatory biomarkers following intervention with gamma-tocopherol [9], soy [10], green tea [11], cholecalciferol [12] and sevelamer [13], the renal community should conduct sufficiently powered RCTs to prove the concept that treatment of persistent inflammation may provide benefit in reducing uremic morbidity and mortality. In a recent RCT involving 2776 hemodialysis patients, the effects of rosuvastatin versus placebo were compared [14]. No effect on mortality was observed despite a small reduction of CRP following statin treatment. However, as the interaction between CRP and the effect of rosuvastatin was not checked, we do not know if the effects of statins on the outcome differ between inflamed and uninflamed dialysis patients.

No large study has yet tested if anti-cytokine therapy affects surrogate biomarkers of inflammation, morbidity, and mortality. However, as therapy targeting IL-1 $\beta$ mediated inflammation not only reduces inflammation biomarkers but also holds promise for the treatment of glycemic control in type 2 diabetic patients [15], it can be speculated that targeted IL-1 antagonism may also benefit uremic patients. In a recent pilot study of 10 dialysis patients that were randomly assigned to receive either the tumour necrosis factor-alpha (TNF- $\alpha$ ) antagonist etanercept or placebo twice weekly for 44 weeks, no significant effects on inflammatory biomarkers were observed [16]. However, as a significant difference in the time-dependent effects of etanercept on prealbumin was observed (levels increased by $20 \%$ in the etanercept group and decreased in the placebo group), favorable effects on nutritional markers may be anticipated. As no adverse side effects were observed, administration of TNF- $\alpha$ receptor antagonism seems safe in selected dialysis patients despite their documented increased risk of infectious complications. Thus, larger studies are now needed to test the effects of selective anti-TNF, IL-1, and IL-6 therapies, respectively, not only on inflammatory and nutritional surrogate markers but also on morbidity and outcome. No doubt, the major problem in such a RCT will be to select the patients with persistent non-infectious uremic inflammation.

\section{Implications for clinical practice}

Until adequately powered RCTs have been performed with anti-inflammatory treatment strategies, no specific pharmacological treatment recommendations for uremic inflammation can be advocated. However, clinicians should be aware of the strong association between persistent inflammation and outcome before carefully evaluating (and if possible treating) the multiple putative causes of persistent inflammation in this patient group. Although the clinician may minimize some aggravating factors that promote inflammation in the context of renal disease, it may not be possible to get rid of inflammation in a clinical situation. Due to the fact that causes both unrelated to dialysis (such as intercurrent infectious and inflammatory complications, peridontitis, and ischemic heart disease) and related to dialysis (such as bioincompatibility, residual renal function, infections of vascular access, dialysis hypotension, impure dialysate, and volume overload) can contribute to uremic inflammation, the clinician needs to carefully evaluate all chronic kidney disease patients with signs of inflammation such as elevated CRP levels. Indeed, a recent study demonstrated lower cardiovascular mortality in dialysis units in which CRP was regularly monitored [17].

\section{Abbreviations}

CRP, C-reactive protein; ESRD, end-stage renal disease; $\mathrm{IL}$, interleukin; RCT, randomized controlled trial; TNF- $\alpha$, tumor necrosis factor-alpha.

\section{Competing interests}

The author declares that he has no competing interests.

\section{Acknowledgements}

The Swedish Medical Research Council supported Peter Stenvinkel's research.

\section{References}

I. Stenvinkel P: Chronic kidney disease: a public health priority and harbinger of premature cardiovascular disease. J Intern Med 2010, 268:456-67.

2. Carrero J, Stenvinkel P: Inflammation in end-stage renal disease-what have we learned in 10 years? Semin Dial 2010, 23:498-509.

3. Carrero JJ, Stenvinkel P: Persistent inflammation as a catalyst for other risk factors in chronic kidney disease: a hypothesis proposal. Clin J Am Soc Nephrol 2009, 4(Suppl I):S49-55.

4. Parekh RS, Plantinga LC, Kao WH, Meoni LA, Jaar BG, Fink NE, Powe NR, Coresh J, Klag MJ: The association of sudden cardiac death with inflammation and other traditional risk factors. Kidney Int 2008, 74:I335-42.

5. Rosas-Ballina M, Tracey $\mathrm{KJ}$ : Cholinergic control of inflammation. J Intern Med 2009, 265:663-79.

6. Zacho J, Tybjaerg-Hansen A, Jensen JS, Grande P, Sillesen H, Nordestgaard BG: Genetically elevated C-reactive protein and ischemic vascular disease. N Engl J Med 2008, 359:| 897-908.

7. Stenvinkel P, Ketteler M, Johnson RJ, Lindholm B, Pecoits-Filho R, Riella M, Heimbürger O, Cederholm T, Girndt M: IL- I 0, IL-6 and TNF-alpha: important factors in the altered cytokine network of end-stage renal disease - the good, the bad and the ugly. Kidney Int 2005, 67:1216-33. 
8. Badiou S, Cristol JP, Jaussent I, Terrier N, Morena M, Maurice F, Leray-Moragues H, Rivory JP, Chalabi L, Delcourt C, Canaud B, Dupuy AM: Fine-tuning of the prediction of mortality in hemodialysis patients by use of cytokine proteomic determination. Clin J Am Soc Nephrol 2008, 3:423-30.

9. Himmelfarb J, Phinney S, Ikizler TA, Kane J, McMonagle E, Miller G: Gamma-tocopherol and docosahexaenoic acid decrease inflammation in dialysis patients. J Renal Nutr 2007, 17:296-304.

10. Fanti P, Asmis R, Stephenson TJ, Sawaya BP, Franke AA. Positive effect of dietary soy in ESRD patients with systemic inflammation - correlation between blood levels of the soy isoflavones and the acute-phase reactants. Nephrol Dial Transpl 2006, $21: 2239-46$.

II. Hsu SP, Wu MS, Yang CC, Huang KC, Liou SY, Hsu SM, Chien CT: Chronic green tea extract supplementation reduces hemodialysis-enhanced production of hydrogen peroxide and hypochlorous acid, atherosclerotic factors, and proinflammatory cytokines. Am J Clin Nutr 2007, 86:1539-47.

FI000 Factor 6

Evaluated by Angela Yee-Moon Wang 12 May 2008

12. Matias PJ, Jorge C, Ferreira C, Borges M, Aires I, Amaral T, Gil C, Cortez J, Ferreira A: Cholecalciferol supplementation in hemodialysis patients: Effects on mineral metabolism, inflammation, and cardiac dimension parameters. Clin J Am Soc Nephrol 2010, 5:905-II.

13. Caglar K, Yilmaz MI, Saglam M, Cakir E, Acikel C, Eyileten T, Yenicesu M, Oguz Y, Vural A, Carrero JJ, Axelsson J, Lindholm B, Stenvinkel $P$ : Short-term treatment with sevelamer increases serum fetuin-a concentration and improves endothelial dysfunction in chronic kidney disease stage 4 patients. Clin J Am Soc Nephrol 2008, 3:6I-8.

14. Fellstrom BC, Jardine AG, Schmieder RE, Holdaas H, Bannister K, Beutler J, Chae DW, Chevaile A, Cobbe SM, Grönhagen-Riska C, De Lima J], Lins R, Mayer G, McMahon AW, Parving HH, Remuzzi G, Samuelsson O, Sonkodi S, Sci D, Süleymanlar G, Tsakiris D, Tesar V, Todorov V, Wiecek A, Wüthrich RP, Gottlow M, Johnsson E, Zannad F; AURORA Study Group: Rosuvastatin and cardiovascular events in patients undergoing hemodialysis. $N$ Engl J Med 2009, 360:1395-407.

Changes Clinical Practice

FI000 Factor 12

Evaluated by Ihab Wahba II May 2009, Peter Stenvinkel I4 May 2009

15. Larsen CM, Faulenbach M, Vaag A, Volund A, Ehses JA, Seifert B, Mandrup-Poulsen T, Donath MY: Interleukin-I-receptor antagonist in type 2 diabetes mellitus. N Engl J Med 2007, 356:1517-26.

FI000 Factor 6

Evaluated by Max Gassmann I3 Jul 2007

16. Don BR, Kim K, Li J, Dwyer T, Alexander F, Kaysen GA. The effect of etanercept on suppression of the systemic inflammatory response in chronic hemodialysis patients. Clin Nephrol 2010, 73:43I-8.

17. Kawaguchi T, Tong L, Robinson BM, Sen A, Fukuhara S, Kurokawa K, Canaud B, Lameire N, Port FK, Pisoni RL: C-Reactive protein and mortality in hemodialysis patients: The Dialysis Outcomes and Practice Patterns Study (DOPPS). Nephron Clin Pract 2010, 1 I7:c167-78. 